\title{
Echoes of the Ecological Handicaps Coal Complex Pollution in Dankuni area, West Bengal, India
}

\author{
Dr. Sushma Sahai \\ Assistant Professor, Department of Geography, Loreto College, Kolkata, West Bengal, India
}

\begin{abstract}
In the course of last few years, media has drawn attention to the crisis faced by the inhabitants of the Dankuni area, Hooghly district, West Bengal, India. Innumerable instances have been brought to the limelight, which clearly indicate wide spread environmental damage in the areas lying in close proximity of the Dankuni Coal Complex. The consequences of development strategies have been extremely adverse as far as environment is concerned. In its lust for immediate gains, the industry is following a myopic policy with no concern for pollution of air, water and land.

While it is important to uphold developmental initiatives like the Dankuni Coal Complex (DCC), it is equally desirable that the residents in the vicinity of such establishments do not suffer. The obsession with quantitative economic growth has bred a natural conflict between environment and development. The very location of DCC is ecologically very sensitive as it has been set up adjacent to the Dankuni Drainage Channel which invariably acts as a receptacle channel for the coal complex effluent. Further accentuating the problem are the low-lying marshes, locally known as the Bhils, whose ecology has been long withstanding the onslaught of mass production, with inadequate attention on the rapidly degrading ecosystem. This is a humble report on the dehumanizing metamorphosis that an industry brings with active support of the Government in the life of simple folks who once considered themselves to be children of the Earth, but today are 'ecologically handicapped.'
\end{abstract}

Keywords: coal complex effluent, Dankuni Coal Complex (DCC), degrading ecosystem, 'ecologically handicapped', pollution

\section{Introduction}

A man emerges from what is locally called a 'peech khal', which illustrates the negative metamorphosis of the Dankuni Drainage Channel (DCC), the tar sticking to his body. The rescued lamb on his shoulders dripping with liquid coal tar released by the biggest coal complex in Asia- The Dankuni Coal Complex, gasping for breath....

This $26 \mathrm{~km}$ long canal is a part of the irrigation network which today is nothing more than a sewage line and has been instrumental in generating adverse impacts on the surrounding landscape.

One of the main causes of the deterioration of the canal has been the DCC, which has been set up on highly productive fertile wetland. In 1990 when it started production the inhabitants felt blessed to have an industry of this kind. But with the passage of time, it has proved to be a curse, causing widespread pollution to more than 23 villages, housing a population of nearly one lakh people.

The West Bengal pollution Control Board (WBPCB) has served a notice to DCC, a Coal India Limited's subsidiary, for violating environmental norms. DCC has also been listed as one of the 334 grossly polluted industries according to WBPCB. (Mrittikaa, 2010)

Since 1991 after the inception of DCC, the inhabitants of the adjacent areas who were all along owners - independent and self-reliant farmers, have been degenerated into serfs collecting their dole of daily bread in the form of temporary and daily wages, since they were dispossessed of their valuable resources , viz., land, water and air.

The fundamental objectives of this study were;

\section{Objectives}

To examine the extent and nature of pollution caused by the Coal Complex, and

To increase public understanding and awareness about industrial pollution.

\section{Methodology}

One hundred and fifty farmers were selected for this study by using random sampling technique. Twenty respondents were randomly selected from each of the fifteen mauzas of the study area. Data was collected with the aid of structured questionnaire and focused group discussions.

A tour along the Dankuni Drainage Channel was undertaken to obtain water samples for laboratory analysis and take an inventory of the outlets of DCC releasing industrial waste into the wetlands. 
An integral part of the study was to gain access to the DCC itself during operation. Several visits of the DCC were undertaken at regular intervals.

\section{Results and Discussion}

\section{Investment in Disaster}

The total affected area as shown in Fig.1 as been divided into three main categories on the basis of the type of pollution, viz,

1) Areas comprehensively polluted

2) Areas essentially affected by air pollution

3) Areas essentially affected by water pollution

In order to provide a more systematic insight in terms of the major pollutants, their impact both economically and ecologically as well as the various actions taken till date, in each of the above mentioned categories is herewith dealt in detail.

1) Areas comprehensively polluted are the seven villages, viz., Chikrand, Dhanpatipur, Naitai, Beledanga, Gobra, Dankuni and Dankuni Bhil. Since they are in close proximity to the DCC they suffer three kinds of pollution, i.e. air, water and land.

2) Areas essentially affected by air pollution comprise the northern part of the concerned area, covering Begampur, Panchgara, Baksa, Adan, Janai, Pairagacha and Bankagacha mauzas.

DCC distills 900 tonnes of coal everyday and produces more than one crore cubic feet of coal gas everyday. This coal gas, which serves as fuel, is partly supplied by DCC to Kolkata and Durgapur through pipeline. The rest is released into the adjacent locality, exposing nearly on lakh people to raw coal gas and toxic chemicals. DCC emits poisonous gases in three different ways:

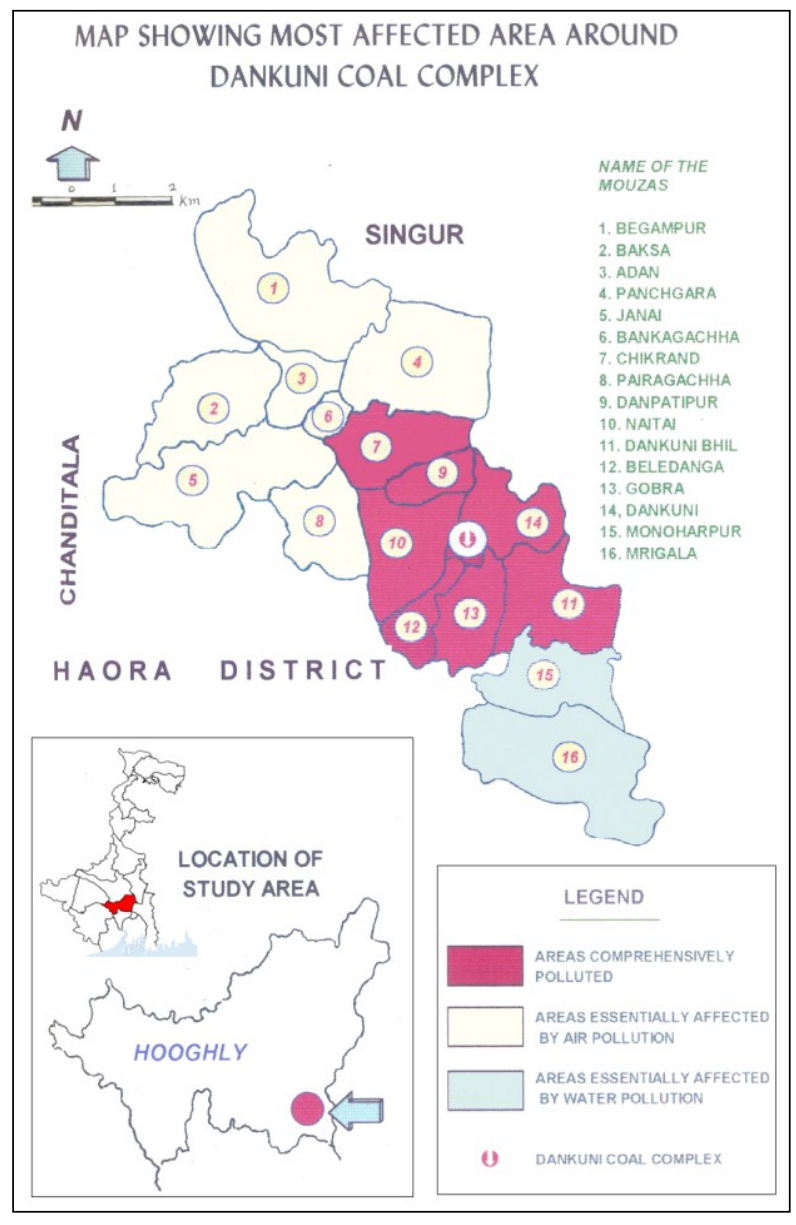

Designed by Author

Figure 1

a) Raw Coal Gas: Raw Coal Gas or Retort gas, which is vented from the retort top of the factory. This gas contains phenol, cresol, pyridine, benzene, toluene, naphthalene, coal tar acids etc., all in vapourized state along with other deadly compounds such hydrocyanic acid gas, ammonia and carbon monoxide. All these compounds are extremely heavy gases and whenever vented settle like a dense fog over the surrounding villages.

The Gobra Anti-Pollution Forum (GAPF), which is spearheading the local campaign against the DCC, reported that DCC annually emits and seldom burns approximately 95 crores cubic feet of Coal Gas and vapourized Coal Tar i.e. average emission of Coal Gas per day is 24 lakh cubic feet.

b) Clean Coal Gas: Apart from emission of raw coal gas, DCC emits a huge amount of so called Clean Coal gas. This gas contains $9.18 \%$ carbon monoxide (by volume) which is highly dangerous to inhale. The purifiers of the factory do not function at their optimum level and thus emit hydrogen sulphide, ammonia and hydrocyanic acid gas as impurities.

c) Burnt Coal Gas: This is emitted during flaring which contains oxides of carbon, sulphur and nitrogen, all of which have adverse health impacts.

According to DCC they do not emit poisonous gas as stated by the inhabitants.DCC stated the fact that by flaring, they are burning the coal gas in the atmosphere. Due to complete combustion this has no health hazard and this does not pollute the adjoining villages. With respect to flaring, DCC authorities have stated that of the 30-35 lakh cubic feet of gas produced per month, only $1 \%-2 \%$ of gas is being vented. 
The DCC representatives explained the principle and need of flaring of gas. The flaring takes place only when there is a fluctuation in demand of gas by Greater Kolkata Gas Supply Corporation or Alloy Steel Plant, Durgapur causing sudden surplus generation of clean coal gas. The technology of flaring of gas adopted by DCC ensures that otherwise escaped gas could cause extensive air pollution.

DCC emits coal gas at midnight and during rainy days. Due to this indiscriminate release of toxic and carcinogenic compounds into the air, the inhabitants suffer from respiratory diseases like asthma, bronchitis and lung cancer. Life in the villages of Dhanpatipur, Beledanga and Jalapara located in the vicinity of the complex has been critically affected, creating a number of dispossessed ecologically handicapped people.

Reflections of these were found in abundance in almost all the mauzas. It is estimated that about 85,000 people from over 23 villages in and around DCC face serious health hazards due to release of carbon monoxide and methane into the air."Frequently at the dead of the night, a dense mist descends and settles on my village" says Sarita Bhat a resident of Jalapara. "It is on these days that we are forced to leave our respective fields, in turn we lose our wages," add a group of cultivators, residing in Dhanpatipur, a village located in close proximity of DCC.

3) Areas essentially affected by water pollution are the pisciculture - dominated mauzas of Monoharpur and Mrigala situated at the southern end of the affected area. It has been pointed out by the GAPF, that polluted water released by DCC in the southern and south-eastern side is causing large scale damage o the standing paddy crops either by direct contact or by the overflowing of water from Durgapur Expressway Borrow pits.

There is no planning for draining thousands of gallons of untreated water discharged from the factory. During its inception stage, water was unscientifically drained into the adjacent fields. After an assessment of the land use map of Dankuni Bhil followed by ground verification it has been authentically established that approximately $90 \%$ of the plots have been receptacle of untreated industrial slurry.Inspite of repeated pleas from the landowners of agricultural plots to construct a boundary wall in order to check the continuous flow of untreated wastewater the DCC turned a deaf ear. This resulted in the transformation of fertile Group - A category of agricultural land into a mere sludge plot, rendering it unproductive.

Thousands of acres of cultivable land have been forced to lay barren due to polluted water discharged by DCC. DCC as one of the major pollutants in the study area, which has both big outlets as well as undeclared drains. It has been estimated through primary data that almost 800 acres of highly productive land is polluted resulting in decline of production of crops. The land which was once covered with green carpet prior to 1990 is virtually barren today. Widespread pollution is eating into employment opportunities of the inhabitants.

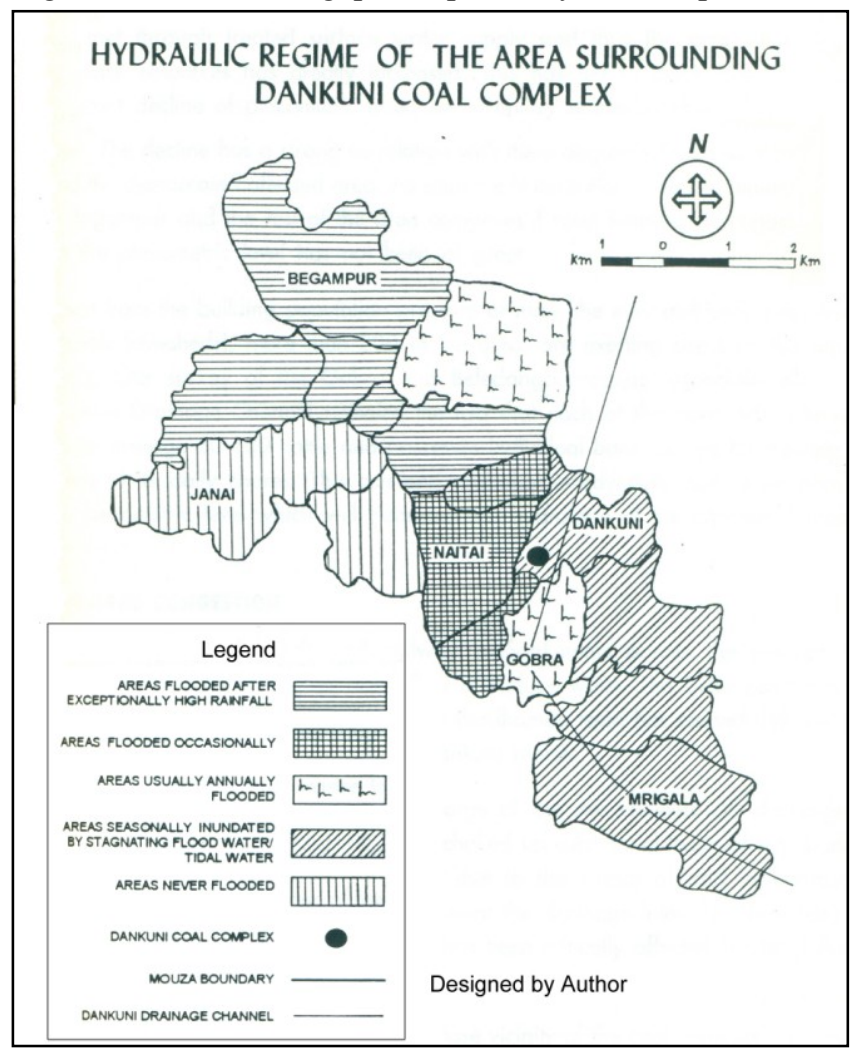

Figure 2

The hydrological regime of the affected mauzas has been illustrated in Fig.2, which has been drawn on the basis of primary data, collected during questionnaire survey. The northern mauzas of the study area, excluding Panchgara, experience floods after exceptionally high rainfall. In contrast the southern part comprising Mrigala, Monoharpur and the low lying marshy area adjacent to the Dankuni Drainage Channel, suffer from seasonal inundation due to stagnation of flood water or tidal ingress. This region housing the DCC has been identified as an area essentially affected by water pollution, due to indiscriminate dumping of untreated industrial wastes into the channel.

Villages like Janai and Pairagacha on the west form highlands, with the land sloping towards the east and south-east. These areas are free from inundation even during periods of heavy rainfall. 
Increase in demand for water due to excessive population pressure is being partly met through treated surface water supply and thus the pressure on sub-surface resources has greatly increased. This has led to excessive withdrawal and consequent decline of the piezometric level. The decline has strong correlation with the level of urbanization.

The critical livelihood stress map of Fig. 3 illustrates that a number of plots around DCC in the villages of Gobra, Naiti, Dhanpatipur and Chikrand have been ruined, seriously affecting 2000 agrarian families. Life for Azar Mollah is a burden as he is suffering losses every year due to shortfall in production from his 15 acres of land. Is there any answer for the hundreds of farmers whom Syed Mollah represents, the question being repeatedly asked, "How can my land revive its lost fertility, how can my land spewing poison be brought under cultivation?" A comprehensive study of the topographical sheets drawn four decades ago showed that the betel gardens stretched for a considerable area in the mauzas of Pairagacha, Adan, Panchgara and Bankagachha. Today due to decrease in cultivable area as well as decline in fertility, betel is cultivated by a few handful. As the yield has reduced by more than half, there is no marketable surplus. This has pushed this area back to the first step of development where the economy was that of subsistence.

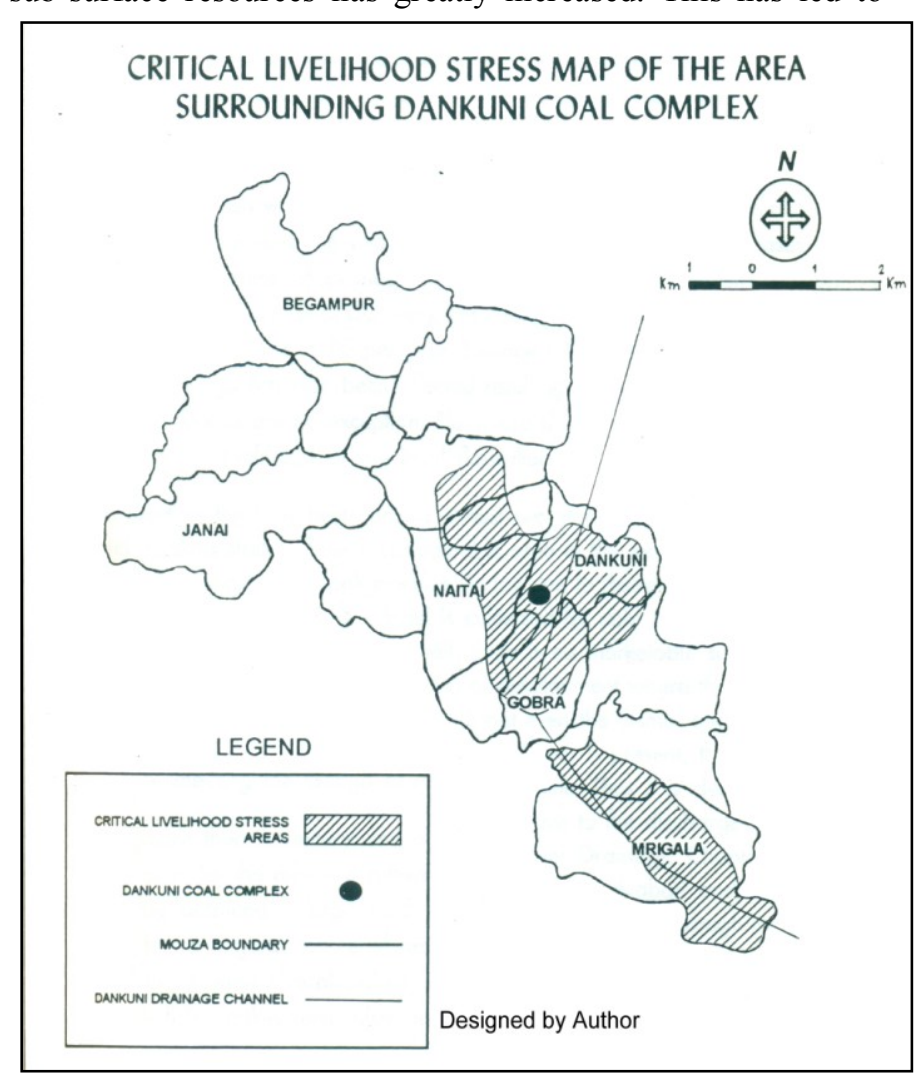

Figure 3

The dismal quantity produced is not suitable for consumption as phenolic odour is present, the colour of rice is blackish and the grain size is small and brittle.

For more than a century and a half the canal has been the main source of irrigation for the cultivated lands as well as for fishing. The fishermen initially obtained a large catch of Shrimp, Gulb, Latha, etc. from this canal, which are a great source of protein. In addition to this snail, oysters, turtles and crabs were also abundant. But today in the words of Jatin Koley, "leave alone fish, snakes have also virtually become extinct."

The geography of tides plays a very important role with respect to discharge of untreated waste. During low tide the canal is absolutely black with an unbearable pungent odour. But during high tide, the water diluted all the pollutants. During ebb tides, the canal was composed of thick tar mixed with tar oil and tar acids. These toxic substances have transformed the chemistry of the canal and rendered it a mere sewage line.

An All India Institute of Public Health official has reported that the phenol concentration in the water discharged by DCC into the canal is very high more than $400 \mathrm{mg}$ per literate official further stated that the water contained alarming levels of cyanide, thyocyanides and phenol.(Source: The Statesman,04.05.1997).

Water samples taken from the Dankuni Drainage Channel and measured by Centre for Study of Man and Environment, revealed that the cyanide content is as high as $9.25 \mathrm{mg}$ per liter which was nine times more than the normal $0.90 \mathrm{mg}$ per litre.

In addition to the carbon compounds, substantial quantities of cow dung are being indiscrimately discharged through small kachha drains into the canal from the khatals (cowsheds) located on either side of the canal. In 1994 - 95 this area had only 51 khatals but after the resettlement of these cowsheds from Kolkata metropolis, initiated by the Government of west Bengal, the numbers have been rapidly escalated to 350 stretching between Dankuni and Gobra. Supporting a total cattle population of around 14, 000, the limelight has shifted on these cowsheds as the major cause of pollution. Around 140-160 tonnes of cow dung and cattle urine from these khatals are finding its way into the canal everyday, exerting excessive pressure on the already fragile ecosystem.

In a span of two decades, DCC has struck at the very roots of the life of majority of the residents. As agriculture and pisiculture are not ecologically feasible, there has been a transformation in the occupational structure. Since most of the workers are unskilled they are forced to migrate to Kolkata, Howrah and Liluah and take up miscellaneous jobs like rickshaw pullers, pottery, carpentry, etc. 


\section{DCC: Blessing or Curse?}

One of the alarming developments witnessed was the fact that coal tar, which had not only smeared large tracts of the canal but also saturated the local ponds, is being widely marketed. The inhabitants waist deep in debt were seen pilfering liquid coal tar from the 132 acre DCC.

For Noor Alam, the head of an eight member family, this is a blessing. Ali thanks the DCC authorities for disposing coal tar from their complex, as it is lucrative for him providing a sum of Rs.300- 450 per tonne. This in turn is sold in the markets of Kolkata for as high as Rs.2000 per tonne. The DCC authorities were aware of this fact, speaking on terms of anonymity, a senior official admitted that a number of DCC workers were in constant league with the pilferers.

A few currency notes have compelled these pilferers to expose themselves to a highly contaminated and hazardous environment. Ganesh Pal and many more from this area were contented agriculturists, but as pollution has eaten into their livelihoods they have been forced to adopt an occupation of this nature. Lesions, bloodshot rashes, blisters and dermatitis are common ailments. It is indeed ironical that the fundamental cause of miseries of the inhabitants has today become a product to cash on, by none other but themselves.

\section{Conclusion}

These wetlands are fragile areas, which are in need of scientific management, because a few more years of passiveness will inflict irreversible damage to this invaluable ecosystem.

The time seems ripe to make appropriate legal provisions by offering compensation to the affected inhabitants due to pollution. Developmental efforts need to recognize the nature of different ecosystems and subsequently formulate plans to suit each of them. The local movement headed by GAPF has gained momentum. Public awareness has accelerated grassroots conservation and endorsed Rene Dubo's slogan of "Think Globally Act Locally." The solution to the problem lies in participatory approach, which has to be strengthened in order to voice their complaints in a collective way.

Environment Impact Assessment has to be adopted in order to estimate the implications of setting up the DCC. There is no doubt that the DCC is one of the key industrial establishments of the Government of West Bengal and perhaps the most important in terms of employment generation. A cost - benefit analysis is needed, to provide a balance between environment and development. Unless such an exercise is carried out we can be sure that the present pattern of so called 'development' will lead us to an explosive situation which will be irreparable and unmanageable. Thus once we replace the premise of 'more is better' with the much more rational axiom that 'enough is best', the constraints of achieving a steady state becomes tangible and productive.

[1]. Mrittikaa, November, 2010.

\section{References}

[2]. The Statesman, 04.05.1997. 